\title{
Impact of COVID-19 pandemic on non-COVID patient's management in urology: a public hospital experience in Mumbai
}

Nikhilesh A. Jibhakate ${ }^{*}$, Sujata K. Patwardhan ${ }^{1}$, Ajit S. Sawant ${ }^{2}$, Hemant R. Pathak ${ }^{3}$, Bhushan P. Patil ${ }^{1}$ and Hitesh Kamal ${ }^{1}$

\begin{abstract}
Background: To evaluate the impact of COVID-19 lockdown on non-COVID urological patient's management in tertiary care urology centres.

Methods: This is an observational study in which data of patients visiting the urology department of all the MCGM run tertiary care hospitals were recorded for the duration of 1 April 2020 to 31 July 2020 and were compared to data of pre-COVID-19 period of similar duration.

Results: There was a decrease of $93.86 \%$ in indoor admissions of urology patients during the COVID-19 lockdown. Indoor admissions for stone disease, haematuria, malignancy accounted for 53.65\%, 15.85\%, 9.75\%, respectively. Elective surgeries had the highest percentage decrease followed by emergency and semi-emergency procedures. There was a reduction of more than $80 \%$ in patients attending outpatient clinics. Stone disease and its consequences were the main reasons for visiting outdoor clinics (39\%). A substantial number of patients presented with flank and abdominal pain (14.8\%) and benign enlargement of the prostate (10.23\%). Malignancy accounted for a very small number of patients visiting outdoor clinics (1.58\%).

Conclusions: COVID-19 pandemic has a profound impact on patient care and education in Urology. There was more than ninety percent reduction in indoor admissions, operative procedures, and outpatient clinics attendance. Once the pandemic is controlled, there will be a large number of patients seeking consultation and management for urological conditions and we should be prepared for it. Surgical training of urology residents needs to be compensated in near future. Long-term impact on urological patient outcome remains to be defined.
\end{abstract}

Keywords: COVID-19, Urology, Pandemic, MCGM, Mumbai

\section{Background}

COVID-19 was declared as a pandemic by the WHO on 11 March 2020 [1]. As of December 2020, the total number of COVID-19 infected patients in India is more than

\footnotetext{
*Correspondence: supernik.2@gmail.com

1 Department of Urology, Seth GS Medical College and KEM Hospital,

Parel, Mumbai, Maharashtra 400012, India

Full list of author information is available at the end of the article
}

ten million. Mumbai, the capital city of Maharashtra, is one of the most affected cities. Municipal Corporation of Greater Mumbai (MCGM) run tertiary care public hospitals includes King Edward Memorial Hospital (KEMH), Lokmanya Tilak Municipal General Hospital (LTMGH), and BYL Nair Charitable Hospital (Nair hospital). These have the busiest urology department in the state of Maharashtra where various urological services are provided. But since the lockdown, which was announced 
on 25 March 2020, these hospitals have been converted into COVID dedicated facilities to deal with the increasing number of COVID-19 patients. Urology wards were converted into medicine wards to accommodate COVID19 patients. Since the beginning of lockdown, all elective outpatient clinics, elective indoor admissions, and elective operative procedures were suspended. As recommended by guidelines, only emergency patients were attended and emergency procedures were performed, which included patients with malignancy, haematuria, urosepsis, renal trauma, acute kidney injury, and complications of other specialities like obstetrics and gynaecology etc. $[2,3]$. Despite lockdown, symptomatic patients presented in outdoor clinics and emergency departments and were attended.

Taking consideration of all the above factors, we compared the data of outdoor clinics, operation theatres, indoor admissions, during the COVID-19 pandemic with data of similar duration in pre-COVID-19 period and studied the impact of COVID-19 pandemic on nonCOVID patient's management in urology in Municipal Corporation of Greater Mumbai (MCGM) run tertiary care urology centres.

\section{Methods}

This is an observational study carried out during the period of lockdown from 1 April 2020 to 31 July 2020. Data of patients visiting the urology department in all the MCGM run tertiary care hospitals were recorded and compared to the data of the pre-COVID-19 period of similar duration. Data included indoor admissions and their indications, elective procedures, emergency procedures, and outpatient clinic attendance.

\section{Results}

\subsection{Impact of COVID-19 on indoor admissions}

Total indoor admissions during the COVID period were 82 as compared to 1337 in the pre-COVID-19 period of the same duration. There was a decrease of $93.86 \%$ in indoor admissions. Among admitted patients in urology wards, $62(75.6 \%)$ were male and $20(24.4 \%)$ were female. Mostly, the patients were in the age group of 51-60 years. The most common indication of admission was symptomatic renal or ureteric calculus disease and accounted for 44 (53.65\%) admissions. Haematuria was the next common indication for indoor admission accounting for 13 (15.85\%) admissions. Malignancy accounted for eight admissions (9.75\%) (Figs. 1, 2, 3 and Tables 1, 2).

\subsection{Impact of COVID-19 on emergency and semi-emergency procedures}

There was a significant reduction in emergency and semiemergency procedures performed during the lockdown. Procedures like cystoscopy and clot evacuation for haematuria, bilateral orchidectomy for metastatic carcinoma of the prostate, TRUS biopsy, catheter insertion had the highest cut-down, while procedures like DJ stenting, percutaneous nephrostomy insertion for AKI, infection and obstruction, DJ stent removal, and catheter change had less percentage decrease (Fig. 4 and Table 3).

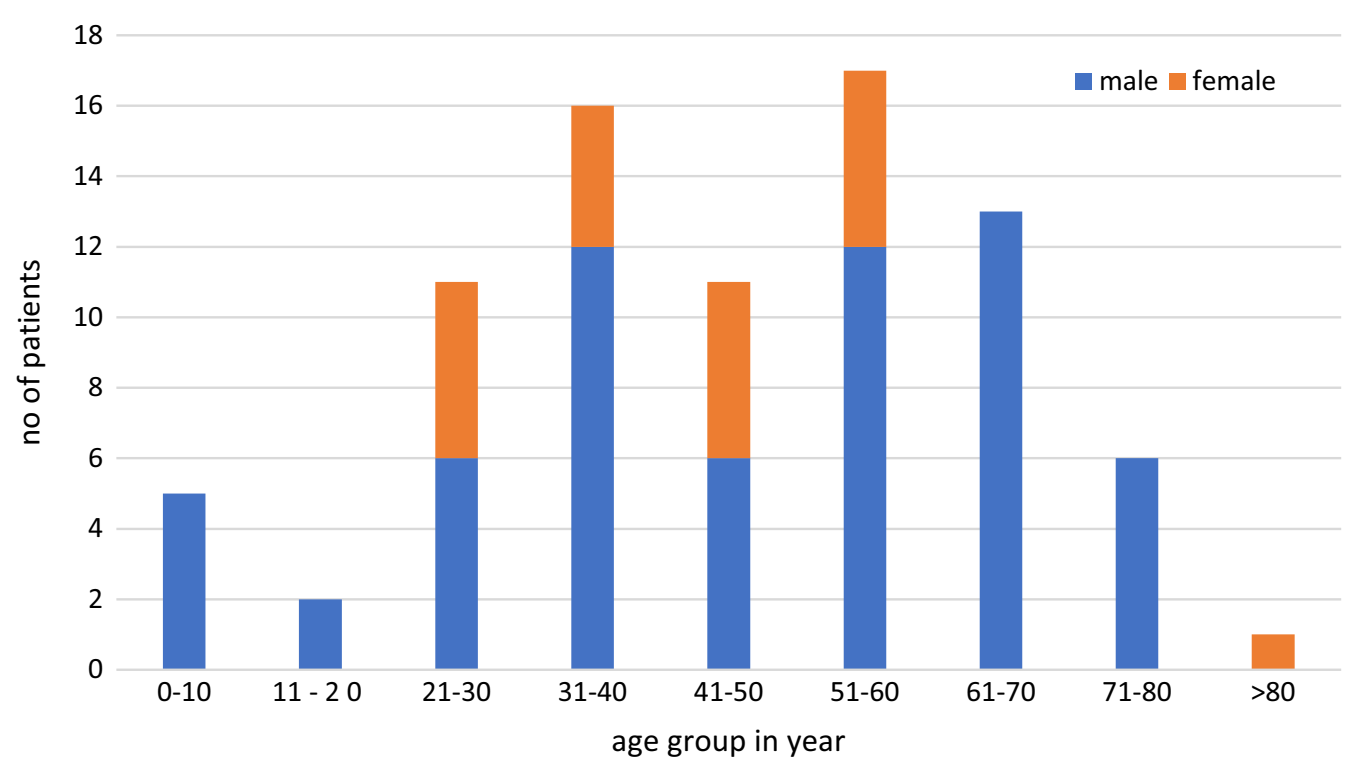

Fig. 1 Demographic profile of indoor patients during COVID period 


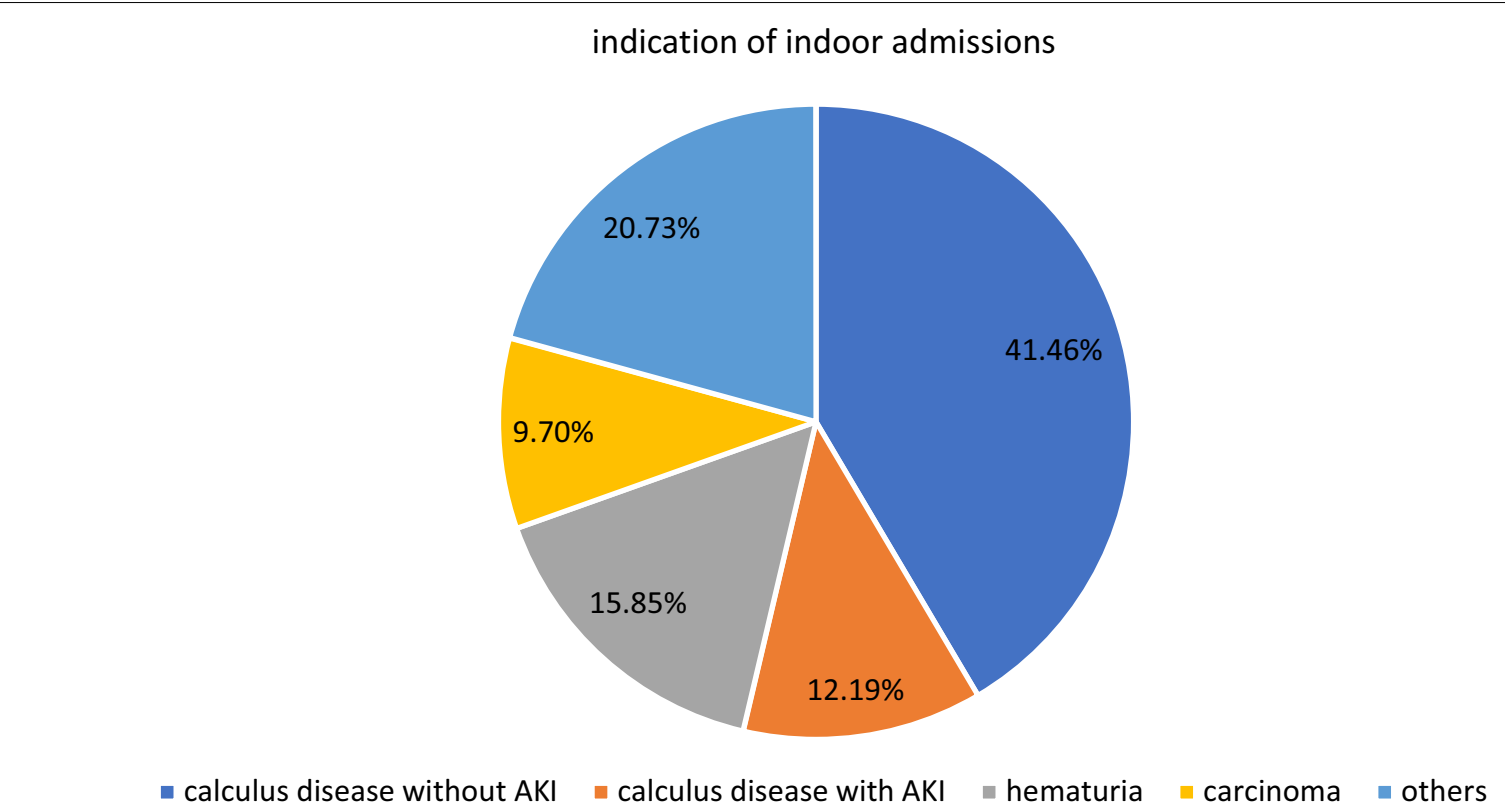

Fig. 2 Percentage distribution according to the indication of indoor patients during COVID period

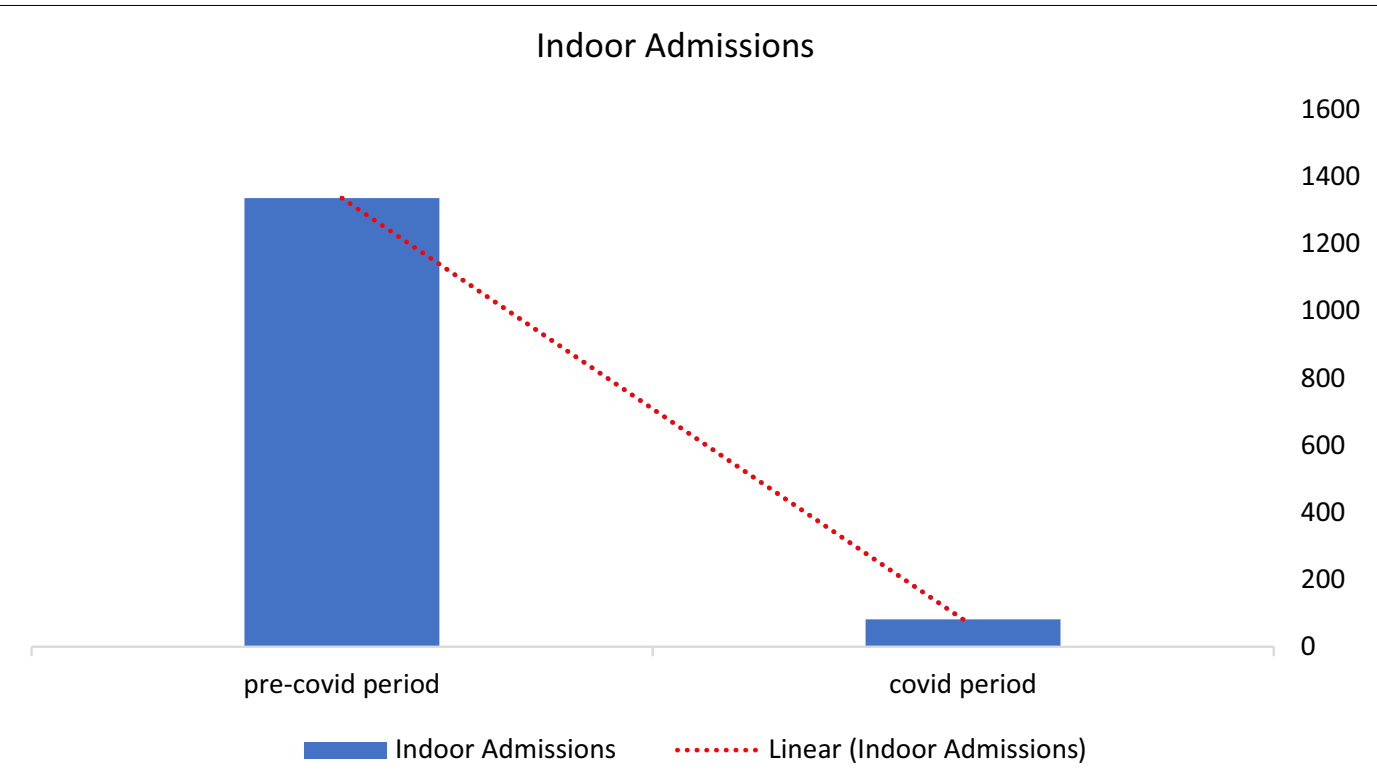

Fig. 3 Percentage decrease in indoor admissions during COVID period

\subsection{Impact of COVID-19 on elective operations}

There was a significant decrease in all types of elective urological surgeries. In particular, percutaneous nephrolithotomy, ureteroscopic lithotripsy, transurethral resection of the prostate, urethroplasty, and renal transplant had the highest cut-down. Instead of definitive elective procedures, DJ stenting and exchange were done in patients with renal and ureteric calculus disease with intractable pain, obstruction, and infection. Patients with BEP and urethral stricture were managed with perurethral catheter and suprapubic catheter change, respectively. Laparoscopic surgeries were strictly avoided due to the risk of transmission among healthcare workers (Fig. 5 and Table 4). 
Table 1 Demographic profile of indoor patients during COVID19 lockdown

\begin{tabular}{lcc}
\hline Age group & Male & Female \\
\hline $0-10$ & 5 & 0 \\
$11-20$ & 2 & 0 \\
$21-30$ & 6 & 5 \\
$31-40$ & 12 & 4 \\
$41-50$ & 6 & 5 \\
$51-60$ & 12 & 5 \\
$61-70$ & 13 & 0 \\
$70-80$ & 6 & 0 \\
81 and above & 0 & 1 \\
Total & 62 & 20 \\
\hline
\end{tabular}

Table 2 Distribution of indoor patients according to the diagnosis

\begin{tabular}{lc}
\hline Diagnosis & No of patients \\
\hline Calculus disease without AKI & 34 \\
Calculus disease with AKI & 10 \\
Urinary tract infection & 4 \\
Carcinoma bladder & 5 \\
Carcinoma penis & 1 \\
Carcinoma prostate & 2 \\
Haematuria & 13 \\
Benign enlargement of prostate & 2 \\
Emphysematous cystitis & 1 \\
Genitourinary tuberculosis & 1 \\
Radiation cystitis & 2 \\
Renal angiomyolipoma & 2 \\
BCG cystitis & 1 \\
Ureteropelvic junction obstruction & 3 \\
Emphysematous pyelonephritis & 1 \\
Total & 82 \\
\hline
\end{tabular}

\subsection{Presentations of patients in outpatient clinics}

Previous outpatient attendance in these hospitals was approximately 3000 patients per month, which was reduced to 1260 patients during four months of the lockdown. Overall, there was more than $80 \%$ reduction in patients visiting outpatient clinics in public hospitals. Stone disease and its consequences were the main reason for visiting outdoor clinics (39\%). A substantial number of patients presented with flank and abdominal pain (14.8\%), benign enlargement of the prostate (10.23\%), lower urinary tract symptoms (4.7\%), and urinary tract infections (5.4\%). Malignancy accounted for a very small number of patients visiting outdoor clinics (1.58\%) (Figs. 6, 7 and Table 5).

\section{Discussion}

\subsection{Effect on indoor admissions, operative procedures, and outpatient clinics}

There was a significant decrease in the number of patients presenting to MCGM public healthcare set-up during the lockdown. The reasons attributed to lockdown, lack of transport, fear of coming to COVID-19 public hospitals, and negative image of public hospitals in local media. The majority of patients who came to hospitals were in the age group of 51 to 60 years and were at higher risk for complications if they got infected with COVID-19 [5]. Patients presented mainly due to complications arising from a benign condition. There was a reduction in patients with malignancy presenting in public hospitals. Malignancy accounted for only $9.7 \%$ of indoor admissions and $1.58 \%$ of the outpatient clinic visits.

There was a significant decrease in indoor admissions and elective operative procedures. As per guidelines issued by both the European Association of Urology (EAU) and the Urology Society of India (USI), stratification of various urological procedures was done. Elective operative procedures for renal and ureteric stones, benign enlargement of the prostate, urethral stricture disease, and renal transplant were affected the most [3, 4]. Semi-emergency procedures like percutaneous nephrostomy insertion, DJ stent insertion and exchange, DJ stent removal, and catheter change were less affected. Patients presenting with urological injuries related to obstetrics and gynaecological procedures had the least decrease in number as they were given priority for transport, diagnosis, and management. Studies done by Devana SK et al., Teoh JY et al., Prasad N et al. showed similar reductions in various urological procedures [6-8]. Similar findings were noted with regard to patients presenting to outpatient clinics. Stone disease and its complications remain the main reason for visiting outdoor clinics (39\%). Substantial patients presented with flank and abdominal pain $(14.8 \%)$, benign enlargement of the prostate (10.23\%), lower urinary tract symptoms, urinary tract infections. Malignancy accounted for a very small number of patients visiting outdoor clinics (1.58\%).

Our approach and management protocols changed because of COVID-19. Lei $\mathrm{S}$ et al. studied the patients undergoing surgeries during COVID-19 and concluded that there was $20 \%$ perioperative mortality in COVID-19 carriers and patients. So, there was a necessity to diagnose carriers of COVID-19 before surgery [9]. However, during the earlier period of lockdown nasal and throat swab RT-PCR and CT scan of the chest were not allowed for asymptomatic and planned operative urology patients due to the limited supply of testing kits. Patients with planned surgery were screened by checklist based on travel history, symptoms, and place of stay (zones), and 


\section{percentage decrease in emergency and semi-emergency procedures}

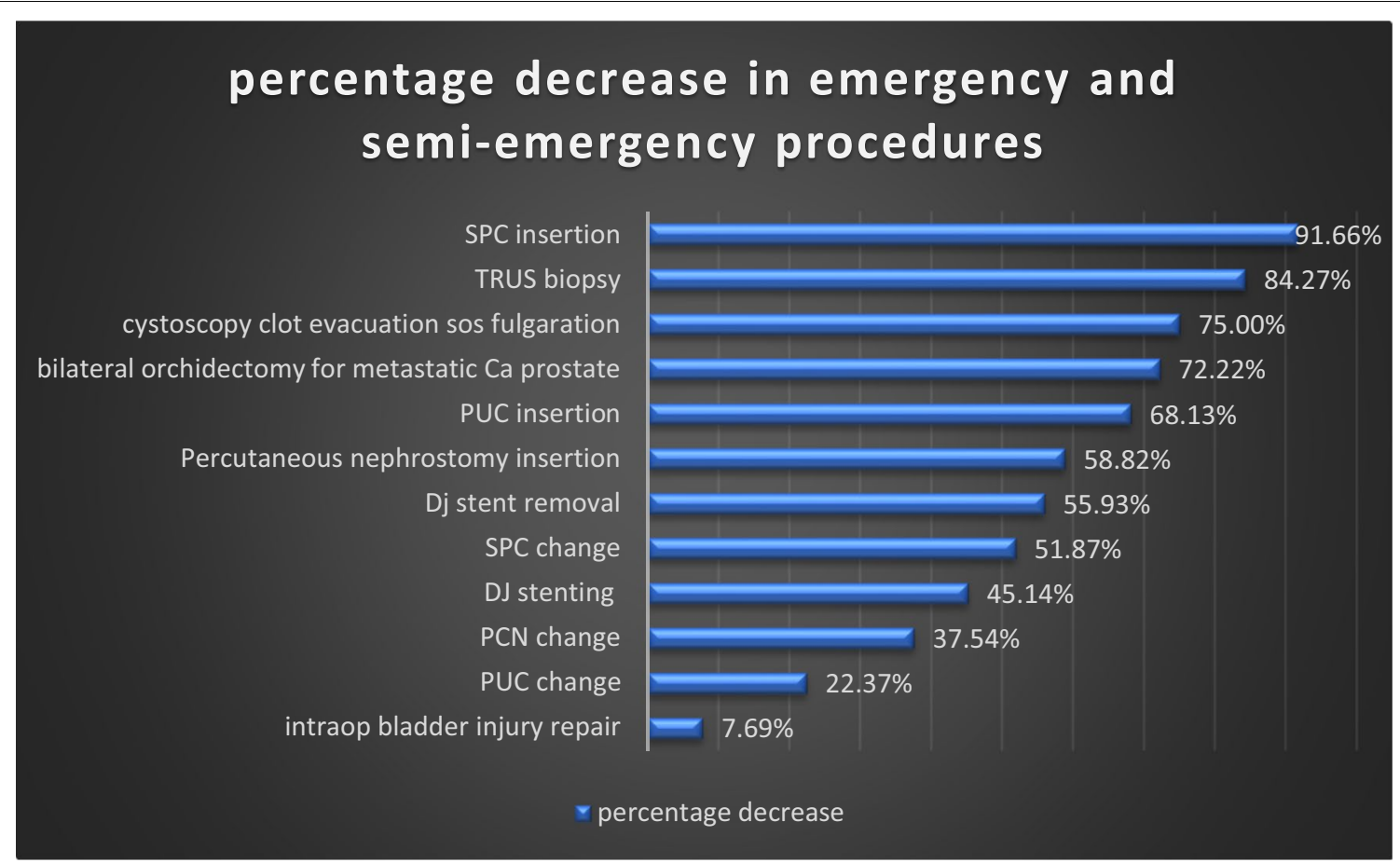

Fig. 4 Percentage decrease in emergency and semi-emergency procedures during COVID period

Table 3 Comparison of emergency and semi-emergency procedures during COVID-19 lockdown and pre-lockdown period

\begin{tabular}{|c|c|c|c|}
\hline Intervention & Pre-lockdown & Lockdown & $\begin{array}{l}\text { Percentage } \\
\text { decrease } \\
(\%)\end{array}$ \\
\hline DJ stenting including exchange & 175 & 96 & 45.14 \\
\hline Percutaneous nephrostomy insertion & 68 & 28 & 58.82 \\
\hline DJ stent removal & 177 & 78 & 55.93 \\
\hline TRUS biopsy & 159 & 25 & 84.27 \\
\hline Bilateral orchidectomy & 18 & 5 & 72.22 \\
\hline Cystoscopy with clot evacuation sos fulgaration & 20 & 5 & 75 \\
\hline Intraop bladder injury repair & 13 & 12 & 7.69 \\
\hline Emergency open nephrectomy for EPN & 2 & 1 & 50 \\
\hline PUC insertion & 91 & 29 & 68.13 \\
\hline SPC insertion & 60 & 5 & 91.66 \\
\hline PCN change & 269 & 168 & 37.54 \\
\hline PUC change & 143 & 111 & 22.37 \\
\hline SPC change & 133 & 64 & 51.87 \\
\hline
\end{tabular}

those who were suspected of having COVID-19 underwent RT-PCR. This was the scenario till late June. Thereafter, RT-PCR and CT scan were easily available and used for screening of indoor patients with no or minimal symptoms of COVID-19 [10].

Most of the urology procedures were done in regional or local anaesthesia. General anaesthesia was avoided due to the risk of aerosol generation and transmission of COVID-19. OT protocols were changed, and donning and doffing areas were set up to reduce the risk of transmission to healthcare personal.

Most elective urological surgeries were postponed including endourological stone surgery, prostate surgeries, reconstructive surgeries, incontinence surgeries, 


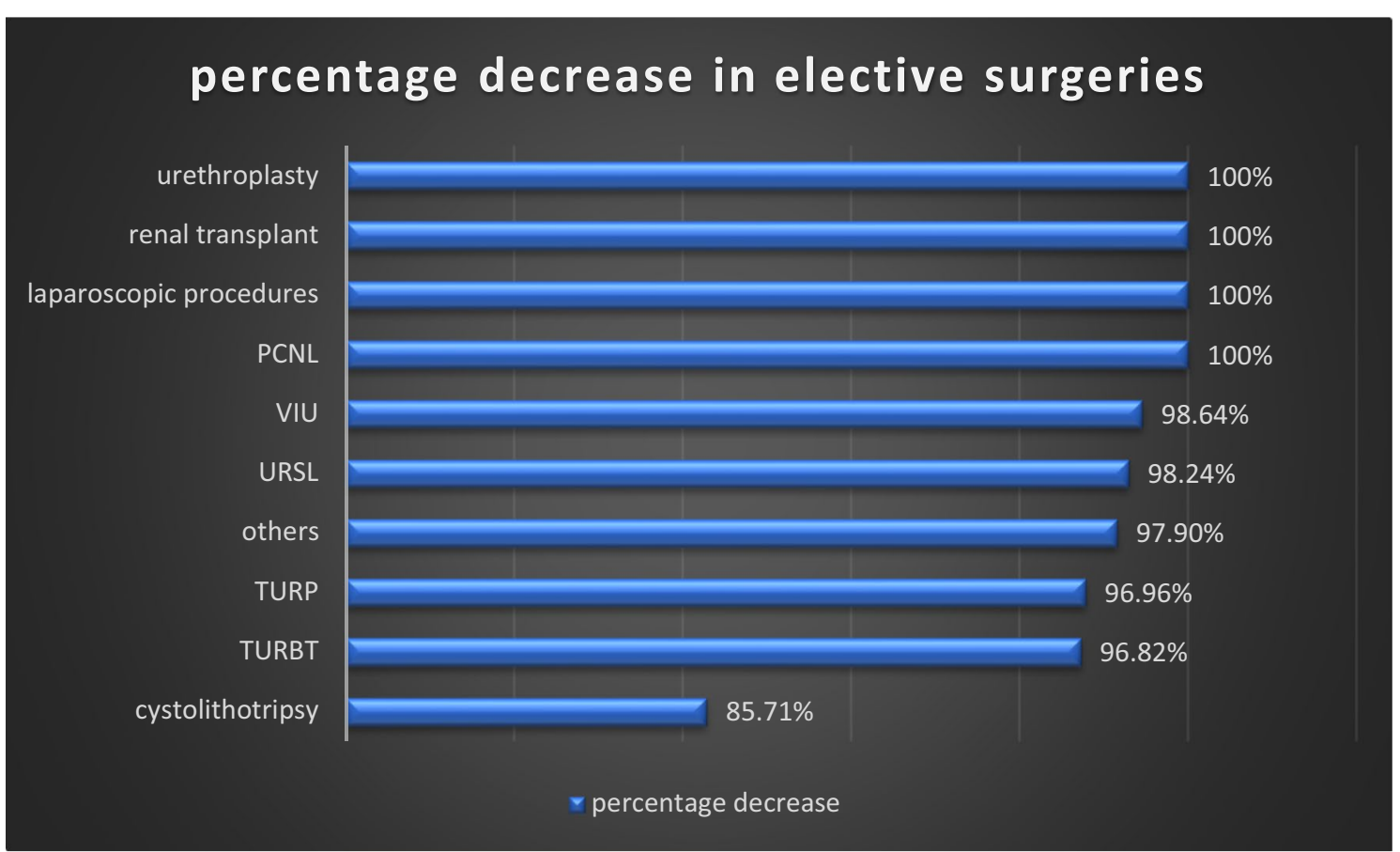

Fig. 5 Percentage decrease in elective surgeries during COVID period

Table 4 Percentage decrease in elective surgeries during COVID-19 lockdown

\begin{tabular}{llll}
\hline OT name & $\begin{array}{l}\text { No. (pre- } \\
\text { lockdown) }\end{array}$ & $\begin{array}{l}\text { No. } \\
\text { (lockdown) }\end{array}$ & $\begin{array}{l}\text { Percentage } \\
\text { decrease }\end{array}$ \\
\hline PCNL & 374 & 0 & 100 \\
URSL & 114 & 2 & 98.24 \\
TURBT & 63 & 2 & 96.82 \\
TURP & 66 & 2 & 96.96 \\
Cystolithotripsy & 35 & 5 & 85.71 \\
VIU & 74 & 1 & 98.64 \\
Laparoscopic procedures & 86 & 0 & 100 \\
Others & 381 & 8 & 97.90 \\
\hline
\end{tabular}

infertility and erectile dysfunction surgeries, and genitourinary prolapse surgeries $[11,12]$. Urinary diversion, treatment of sepsis, supportive treatment, and care were the cornerstone of management. Percutaneous nephrostomy and DJ stenting for the obstructive stone disease were initially attempted under local anaesthesia and if necessary regional or general anaesthesia was given. Acute urinary retention was managed by the insertion of a urethral or suprapubic catheter under local anaesthesia. In case of clot retention due to bladder cancer, prostate cancer, or benign enlargement of the prostate cystoscopy clot evacuation and haemostasis were performed. Definitive surgery was postponed for $2-3$ months. Neoadjuvant chemotherapy was given to patients with malignancy as indicated. Patients who were scheduled for Radical Prostatectomy were given $\mathrm{GnRH}$ analogue. As per guidelines of EAU, BAUS, USANZ, radical prostatectomy for lowrisk and intermediate-risk prostate cancer was postponed for 3 months. Children and patients with malignancy, trauma, obstetric, and gynaecological emergencies were given priority for treatment.

As per guidelines recommended by the Urology Society of India, laparoscopy and robotic procedures were avoided due to the risk of aerosol transmission $[13,14]$. The live renal transplant program was temporarily suspended in all public hospitals as per MoHFW's Advisory for Hospitals and Medical Institutions dated 03-03-2020 [15]. The long-term impact of delay in urological procedures will require further studies.

\subsection{Effect on the training of residents}

All urology residents were posted for COVID-19-related duties in rotation which affected the training of residents in routine and emergency urological surgeries. A nationwide survey of the impact of COVID-19 on urology residency in India by Cheriyan A. and Kumar S. concluded that there is a $90 \%$ reduction in caseload and surgical exposure leading to a negative impact on surgical training [16]. Effect on academic learning was less profound as online webinars and teaching sessions were increased as 


\section{presentation of patients to outpatient clinics}

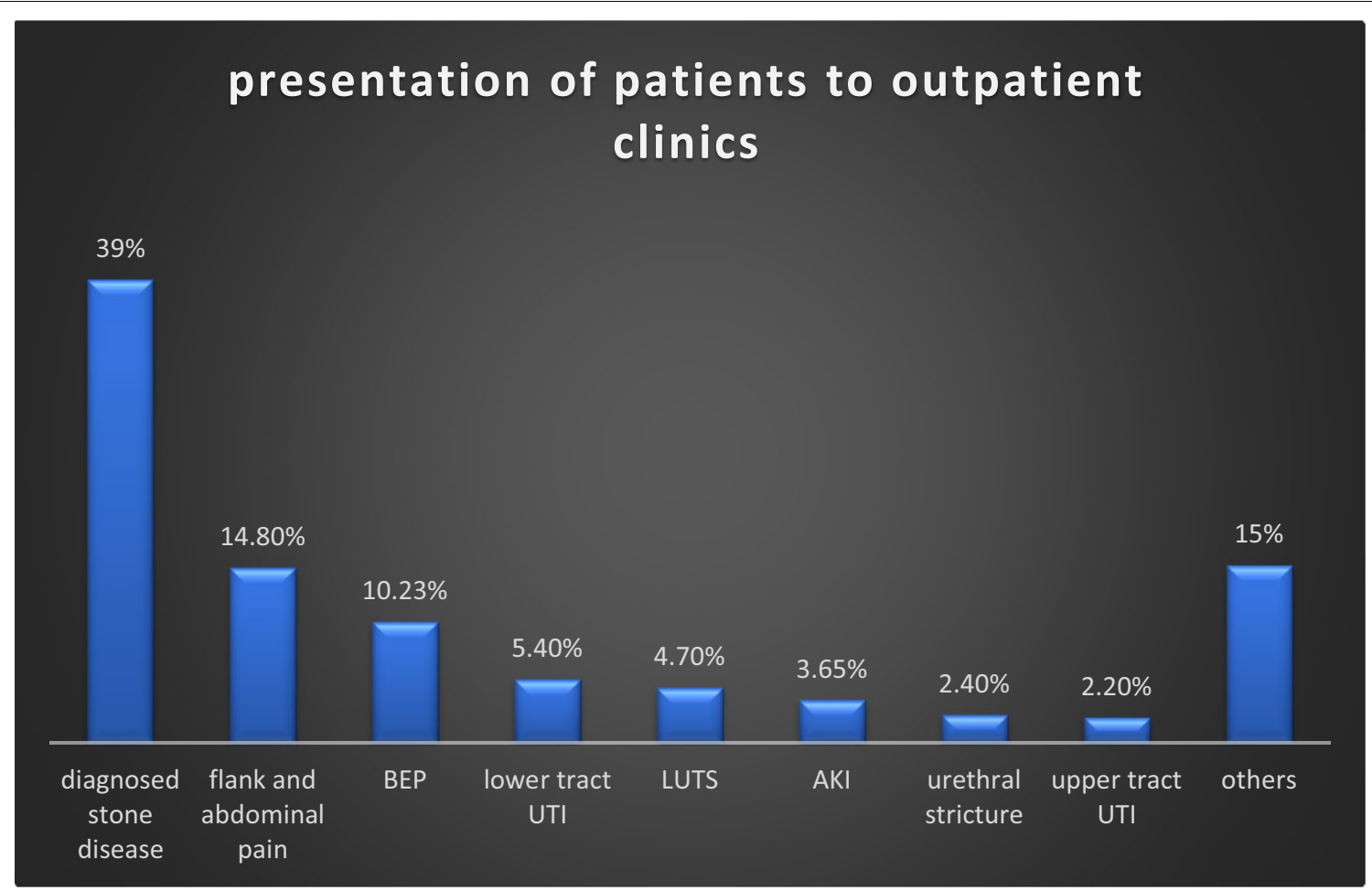

Fig. 6 Percentage distribution according to presentation in the outpatient clinic during COVID period

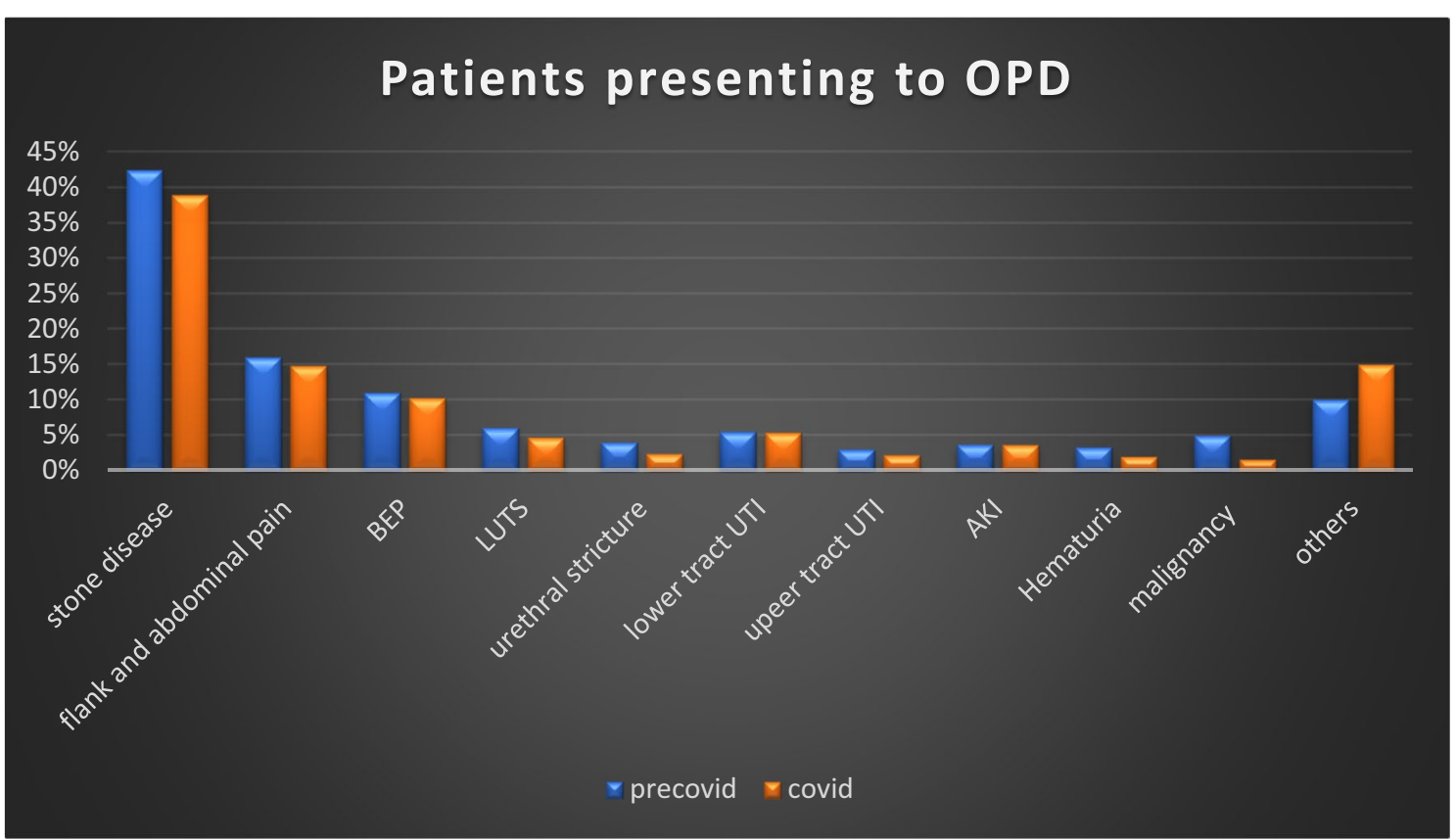

Fig. 7 Comparison of patients attending OPD during COVID and pre-COVID period 
Table 5 Distribution of patients attending outpatient clinics

\begin{tabular}{lr}
\hline Diagnosis & No \\
\hline Flank and abdominal pain & 187 \\
Diagnosed stone disease & 492 \\
BEP & 129 \\
LUTS & 60 \\
Acute urinary retention & 33 \\
Haematuria & 25 \\
AKI & 46 \\
EPN & 8 \\
Pyelonephritis & 20 \\
Lower urinary tract infection & 69 \\
RCC & 3 \\
Ca bladder & 8 \\
Urethral stricture & 31 \\
Carcinoma prostate & 8 \\
Carcinoma penis & 1 \\
Angiomyolipoma & 2 \\
Other & 138 \\
Total & 1260 \\
\hline
\end{tabular}

compared to pre-COVID era, and the writing of scientific project papers and textbooks was done more frequently.

\section{Conclusions}

COVID-19 pandemic has a profound impact on patient care and education in urology. There was more than ninety percent reduction in indoor admissions, operative procedures, and outpatient clinics attendance. Stone disease was the most common indication for indoor admission (53.65\%) and outpatient clinic visits (39\%). Malignancy accounted for $9.75 \%$ of indoor admissions and $1.58 \%$ of outpatient clinics visit. DJ stenting was the most common operative procedure performed. Once the pandemic is controlled, there will be a large number of patients seeking consultation and management for urological conditions and we should be prepared for it. Surgical training of urology residents needs to be compensated in near future. Long-term impact on urological patient outcome remains to be defined.

\begin{abstract}
Abbreviations
COVID-19: Coronavirus disease; MCGM: Municipal Corporation of Greater Mumbai; DJ: Double J; PCN: Percutaneous nephrostomy; EPN: Emphysematous pyelonephritis; PUC: Perurethral catheter; SPC: Suprapubic catheter; TURBT: Transurethral resection of bladder tumour; VIU: Visual internal urethrotomy; TURP: Transurethral resection of the prostate; PCNL: Percutaneous nephrolithotomy; URSL: Ureterorenoscopic lithotripsy; LUTS: Lower urinary tract symptoms; RT-PCR: Reverse transcriptase polymerase chain reaction.
\end{abstract}

\section{Acknowledgements}

Not applicable. I intend to submit the manuscript to 'African Journal of Urology', and that it is not currently under consideration elsewhere.

\section{Authors' contributions}

NJ performed conception, drafted the work, and revision of work. SKP, ASS, and HRP designed the work and interpreted the data. BPP performed acquisition, analysis, and revision of work. HK interpreted the data. All authors read and approved the final manuscript.

\section{Funding}

The study was not supported financially by anybody.

Data availability

The datasets used and/or analysed during the current study are available from the corresponding author on reasonable request.

\section{Declarations}

Ethics approval and consent to participate

Ethics committee name - Institutional Ethics Committee, KEM hospital. It is retrospective observational study based on the standard clinical practices with no deviation from it and does not involve patients directly, and hence, the ethics approval is waived off by Institutional Ethics committee.

\section{Consent for publication}

It is retrospective observational study, so the consent is not applicable.

\section{Competing interests}

The authors declare that they have no competing interests in this section.

\section{Author details}

'Department of Urology, Seth GS Medical College and KEM Hospital, Parel, Mumbai, Maharashtra 400012, India. ${ }^{2}$ Department of Urology, Lokmanya Tilak Medical College and General Hospital, Mumbai, Maharashtra, India. ${ }^{3}$ Department of Urology, TNMC and BYL Nair Ch. Hospital, Mumbai, Maharashtra, India.

Received: 19 January 2021 Accepted: 12 June 2021

Published online: 06 July 2021

\section{References}

1. Worldometer. COVID-19 coronavirus pandemic. Worldometer Web site; April 12, 2020

2. Goldman HB, Haber GP (2020) Recommendations for tiered stratification of urological surgery urgency in the COVID-19 era. J Urol 204:11

3. Kumar A. Corona virus disease USI information centre. https://usi.org.in/ New/Spe_pdf/USI\%20Corona\%20advise\%20edited.pdf. Accessed 20 Sept 2020

4. Ribal MJ, Cornford P, Briganti A, Knoll T, Gravas S, Babjuk M et al (2020) European association of urology guidelines office rapid reaction group: an organization- wide collaborative effort to adapt the European association of urology guidelines recommendations to the coronavirus disease 2019 era. Eur Urol 78:21-28

5. Cornavirus Disease (COVID-19) Pandemic. https://www.who.int/emerg encies/diseases/novel-coronavirus-2019. Accessed 22 Sept 2020

6. Devana SK, Chaudhary K, Sharma AP, Singh SK (2020) Changing urological practice during COVID-19. Indian J Urol 36:153-158

7. Teoh JY, Ong WLK, Gonzalez-Padilla D, Castellani D, Dubin JM, Esperto F, Campi R, Gudaru K, Talwar R, Okhunov Z, Ng CF, Jain N, Gauhar V, Wong MC, Wroclawski ML, Tanidir Y, Rivas JG, Tiong HY, Loeb S, UroSoMe Working Group (2020) A global survey on the impact of COVID-19 on urological services. Eur Urol 78(2):265-275. https://doi.org/10.1016/j.eururo.2020. 05.025

8. Prasad N, Bhatt M, Agarwal SK, Kohli HS, Gopalakrishnan N, Fernando E, Sahay M, Rajapurkar M, Chowdhary AR, Rathi M, Jeloka T, Lobo V, Singh S, Bhalla AK, Khanna U, Bansal SB, Rai PK, Bhawane A, Anandh U, Singh AK, Shah B, Gupta A, Jha V (2020) The adverse effect of COVID pandemic on the care of patients with kidney diseases in India. Kidney Int Rep 5(9):1545-1550. https://doi.org/10.1016/j.ekir.2020.06.034

9. Lei S, Jiang F, Su W, Chen C, Chen J, Mei W et al (2020) Clinical figure 2: algorithm for management of urological patients during COVID era characteristics and outcomes of patients undergoing surgeries during 
the incubation period of COVID-19 infection. E Clin Med. https://doi.org/ 10.1016/j.eclinm.2020.100331

10. Containment Plan for Large Outbreaks: Novel Coronavirus Disease 2019 (COVID-19). Ministry of Health and Family Welfare Government of India. https://www.mohfw.gov.in/pdf/3ContainmentPlanforLargeOutbreaksof COVID19Final.pdf. Accessed 22 Sept 2020

11. Ficarra V, Novara G, Abrate A et al (2020) Urology practice during COVID19 pandemic. Minerva Urol Nefrol. https://doi.org/10.23736/S0393-2249. 20.03846-1

12. Stensland KD, Morgan TM, Moinzadeh A et al (2020) Considerations in the triage of urologic surgeries during the COVID-19 pandemic. Eur Urol 77:663

13. Updated Intercollegiate General Surgery Guidance on COVID-19. https:// www.rcseng.ac.uk/coronavirus/joint-guidancefor-surgeons-v2. Accessed 24 Sept 2020
14. Mottrie A. ERUS (EAU Robotic Urology Section) Guidelines During COVID-19 Emergency. https://uroweb.org/wp-content/uploads/ ERUS-guidelines-for-COVID-def.pdf. Accessed 20 Sept 2020

15. https://www.mohfw.gov.in/pdf/AdvisoryforHospitalsandMedicallnstitutio ns.pdf. Accessed 16 Sept 2020

16. Cheriyan A, Kumar S (2020) Impact of COVID-19 on urology residency in India-Results of a nationwide survey. Indian J Urol 36:243-245

\section{Publisher's Note}

Springer Nature remains neutral with regard to jurisdictional claims in published maps and institutional affiliations.

\section{Submit your manuscript to a SpringerOpen ${ }^{\circ}$ journal and benefit from:}

- Convenient online submission

- Rigorous peer review

- Open access: articles freely available online

- High visibility within the field

- Retaining the copyright to your article

Submit your next manuscript at $\boldsymbol{\nabla}$ springeropen.com 